\title{
Comparison tests for the determination of the viscosity values of reference liquids by capillary viscometers and stabinger viscometer SVM 3001
}

\author{
Gokce Sevim Sariyerli*, Orhan Sakarya, and Umit Yuksel Akcadag \\ The Scientific and Technical Research Council of Turkey, National Metrology Institute (TUBITAK UME), Gebze, Turkey
}

Received: 27 December 2017 / Accepted: 13 March 2018

\begin{abstract}
The present study was realized for measuring viscosities of reference liquids using capillary viscometers and Stabinger viscometer SVM 3001 with viscosity interval between $1 \mathrm{~mm}^{2} / \mathrm{s}$ and $5000 \mathrm{~mm}^{2} / \mathrm{s}$ with temperatures from $20^{\circ} \mathrm{C}$ to $80^{\circ} \mathrm{C}$. Based on our measurement with various liquids, we determine the viscosity values and compare both of the results. The aim of this study to evaluate the results of the primary level viscosity measurement system and stabinger viscometer and to compare the measurement results due to the providing traceability of Stabinger viscometer by TUBITAK UME. An increasing number of national metrology institutes and accredited laboratories provide viscometer calibration with reference liquids in a wide viscosity range. It is a common practice to use the viscosity of water as the metrological basic of viscometry. The national standard of viscosity provided by TUBITAK UME consists of a set of ubbelohde viscometers covering the measuring range of kinematic viscosities from about $0.5 \mathrm{~mm}^{2} / \mathrm{s}$ to $100000 \mathrm{~mm}^{2} / \mathrm{s}$. At the low viscosity, long - capillary viscometers are used as primary standards which are directly calibrated water.
\end{abstract}

Keywords: viscosity / capillary / stabinger viscometer / traceability / metrology

\section{Introduction}

Viscosity is the ratio of the shearing stress $(\mathrm{F} / \mathrm{A})$ to the velocity gradient $\left(\Delta v_{x} / \Delta z\right.$ or $\left.d v_{x} / d z\right)$ in a fluid. The more usual form of this relationship, called Newton's equation, states that the resulting shear of a fluid is directly proportional to the force applied and inversely proportional to its viscosity. The similarity to Newton's second law of motion $(F=$ m.a) should be apparent.

Kinematic viscosity is a measure of the resistive flow of a fluid under the influence of gravity. It is frequently measured using a device called a capillary viscometer. When two fluids of equal volume are placed in identical capillary viscometers and allowed to flow under the influence of gravity, a viscous fluid takes longer than a less viscous fluid to flow through the tube.

Mathematical expression describing the flow of fluids in circular tubes was determined as below:

$$
q_{m}=\frac{\pi \Delta \operatorname{Pr}^{4}}{8 \eta l}
$$

\footnotetext{
* Corresponding author: gokce.sariyerli@tubitak.gov.tr
}

- directly proportional to the pressure difference $(\Delta P)$ between the ends of the tube;

- inversely proportional to the length $(\ell)$ of the tube; - inversely proportional to the viscosity $(\eta)$ of the fluid; - proportional to the fourth power of the radius $\left(r^{4}\right)$ of the tube.

Viscosity measurements are important in many fields of both industry and research. Many manufacturers now regard viscometers as a crucial part of their research, development, and process control programs. They know that viscosity measurements are often the quickest, most accurate and most reliable way to analyze some of the most important factors affecting product performance.

Viscosity is a technological quantity which is related with the flow of matter. The viscosity measurements find great importance in rheology. A frequent reason for the measurement of rheological properties can be found in the area of quality control, where raw materials must be consistent from batch to batch. For this purpose, flow behavior is an indirect measure of product consistency and quality.

Another reason for making flow behavior studies is that a direct assessment of processability can be obtained. For example, a high viscosity liquid requires more power to 
pump than a low viscosity one. Knowing its rheological behavior, therefore, is useful when designing pumping and piping systems.

It has been suggested that rheology is the most sensitive method for material characterization because flow behavior is responsive to properties such as molecular weight and molecular weight distribution. This relationship is useful in polymer synthesis, for example, because it allows relative differences to be seen without making molecular weight measurements.

The instruments for viscosity measurements are designed to determine "a fluid's resistance to flow," a fluid property defined above as viscosity. The fluid flow in a given instrument geometry defines the strain rates, and the corresponding stresses are the measure of resistance to flow. If strain rate or stress is set and controlled, then the other one will, everything else being the same, depend on the fluid viscosity. If the flow is simple (one dimensional, if possible) such that the strain rate and stress can be determined accurately from the measured quantities, the absolute dynamic viscosity can be determined; otherwise, the relative viscosity will be established. For example, the fluid flow can be set by dragging fluid with a sliding or rotating surface, falling body through the fluid, or by forcing the fluid (by external pressure or gravity) to flow through a fixed geometry, such as a capillary tube, annulus, a slit (between two parallel plates), or orifice. The corresponding resistance to flow is measured as the boundary force or torque, or pressure drop. The flow rate or efflux time represents the fluid flow for a set flow resistance, like pressure drop or gravity force [1].

The basic principle of all viscometers is to provide as simple flow kinematics as possible such as the utilization of one-dimensional flows in order to characterize and determine the shear strain rate as accurately, easily and as independently of the fluid type as possible. The resistance to such flow is measured, and thereby the shearing stress is determined. The shear viscosity is then easily found as the ratio between the shearing stress and the corresponding shear strain rate [1].

Glass capillary viscometers are very simple and inexpensive. Their geometry resembles a U-tube with at least two reservoir bulbs connected to a capillary tube passage with inner diameter $D$. The fluid is drawn up into one bulb reservoir of known volume, $V_{0}$, between etched marks. The efflux time, $\Delta t$, is measured for that volume to flow through the capillary under gravity. Various kinds of commercial glass capillary viscometers, like CannonFenske type or similar, can be purchased from scientific and/or supply stores. They are the modified original Ostwald viscometer design in order to minimize certain undesirable effects, to increase the viscosity range, or to meet specific requirements of the tested fluids, like opacity, etc. Glass capillary viscometers are often used for lowviscosity fluids [1].

In this study, it has a great importance to find the closest values of kinematic viscosity for both measurements to present the relation of Ubbelohde viscometer and Stabinger viscometer and provide the traceability of the Stabinger viscometer with our own primary viscosity measurement system.
Table 1. APS3 Reference liquid (Method 2).

\begin{tabular}{lll}
\hline Temperature $\left({ }^{\circ} \mathrm{C}\right)$ & $\begin{array}{c}\text { Kinematic } \\
\text { viscosity }\left(\mathrm{mm}^{2} / \mathrm{s}\right)\end{array}$ & $\mathrm{U}^{\prime}(\boldsymbol{v})(\%)$ \\
\hline 20 & 4.537 & 2 \\
25 & 4.006 & 2 \\
40 & 2.880 & 2 \\
60 & 2.023 & 2 \\
80 & 1.511 & 2 \\
\hline
\end{tabular}

Table 2. APN7.5 Reference liquid (Method 2).

\begin{tabular}{lll}
\hline Temperature $\left({ }^{\circ} \mathrm{C}\right)$ & $\begin{array}{c}\text { Kinematic } \\
\text { viscosity }\left(\mathrm{mm}^{2} / \mathrm{s}\right)\end{array}$ & $\mathrm{U}^{\prime}(\boldsymbol{v})(\%)$ \\
\hline 20 & 12.42 & 2 \\
25 & 10.52 & 2 \\
40 & 6.785 & 2 \\
60 & 4.246 & 2 \\
80 & 2.917 & 2 \\
\hline
\end{tabular}

Table 3. APN26 Reference liquid (Method 2).

\begin{tabular}{lll}
\hline Temperature $\left({ }^{\circ} \mathrm{C}\right)$ & $\begin{array}{c}\text { Kinematic } \\
\text { viscosity }\left(\mathrm{mm}^{2} / \mathrm{s}\right)\end{array}$ & $\mathrm{U}^{\prime}(\boldsymbol{v})(\%)$ \\
\hline 20 & 61.70 & 2 \\
25 & 49.65 & 2 \\
40 & 27.78 & 2 \\
60 & 14.89 & 2 \\
80 & 9.08 & 2 \\
\hline
\end{tabular}

\section{Methods}

\subsection{Reference liquids and viscometers}

Reference liquids were obtained Paragon Scientific Ltd., UK. The names of the liquids are APS3, APN7.5, APN 415 and APN26.

The comparison tests were realized at $20^{\circ} \mathrm{C}, 25^{\circ} \mathrm{C}$, $40^{\circ} \mathrm{C}, 60^{\circ} \mathrm{C}$ and $80^{\circ} \mathrm{C}$ using the reference liquids (APS3, APN26, APN7.5 and APN 415) by both Ubbelohde viscometers and Stabinger viscometer SVM 3001. For Method 2, the results of the reference liquids (APS 3, APN 26, APN 7.5 and APN 415) were given in Table 1, Table 2, Table 3 and Table 4.

Method 1, the two Ubbelohde viscometers with type 0B $\left(K=0.005 \mathrm{~mm}^{2} / \mathrm{s}^{2}\right)$ were used for the determination of kinematic viscosity values of APS3 at the temperatures mentioned above (Tab. 5).

The two Ubbelohde viscometers with type 2 $\left(K=0.1 \mathrm{~mm}^{2} / \mathrm{s}^{2}\right)$ were used for the determination of kinematic viscosity values of APN26 at the temperatures of $20^{\circ} \mathrm{C}, 25^{\circ} \mathrm{C}, 40{ }^{\circ} \mathrm{C}$, and with type $1 \mathrm{C}\left(K=0.03 \mathrm{~mm}^{2} / \mathrm{s}^{2}\right)$ at the temperatures of $60^{\circ} \mathrm{C}, 80^{\circ} \mathrm{C}$ (Tab. 6). 
Table 4. APN415 Reference liquid (Method 2).

\begin{tabular}{lcl}
\hline Temperature $\left({ }^{\circ} \mathrm{C}\right)$ & $\begin{array}{c}\text { Kinematic } \\
\text { viscosity }\left(\mathrm{mm}^{2} / \mathrm{s}\right)\end{array}$ & $\mathrm{U}^{\prime}(\boldsymbol{v})(\%)$ \\
\hline 20 & 1362.0 & 2 \\
25 & 978.6 & 2 \\
40 & 407.6 & 2 \\
60 & 157.8 & 2 \\
80 & 73.77 & 2 \\
\hline
\end{tabular}

Table 5. APS3 Reference liquid (Method 1).

\begin{tabular}{lll}
\hline Temperature $\left({ }^{\circ} \mathrm{C}\right)$ & \multicolumn{1}{c}{ Kinematic } \\
viscosity $\left(\mathrm{mm}^{2} / \mathrm{s}\right)$ & $\mathrm{U}^{\prime}(\boldsymbol{v})(\%)$ \\
\hline 20 & 4.5398 & 0.23 \\
25 & 4.0089 & 0.23 \\
40 & 2.8948 & 0.22 \\
60 & 2.0287 & 0.22 \\
80 & 1.5155 & 0.20 \\
\hline
\end{tabular}

Table 6. APN26 Reference liquid (Method 1).

\begin{tabular}{lll}
\hline Temperature $\left({ }^{\circ} \mathrm{C}\right)$ & $\begin{array}{c}\text { Kinematic } \\
\text { viscosity }\left(\mathrm{mm}^{2} / \mathrm{s}\right)\end{array}$ & $\mathrm{U}^{\prime}(\boldsymbol{v})(\%)$ \\
\hline 20 & 61.7185 & 0.32 \\
25 & 49.6582 & 0.32 \\
40 & 27.8119 & 0.29 \\
60 & 14.9192 & 0.29 \\
80 & 9.0941 & 0.28 \\
\hline
\end{tabular}

The two Ubbelohde viscometers with type $1 \mathrm{C}$ $\left(K=0.03 \mathrm{~mm}^{2} / \mathrm{s}^{2}\right)$ were used for the determination of kinematic viscosity values of APN7.5 at the temperatures of $20^{\circ} \mathrm{C}, 25^{\circ} \mathrm{C}, 40^{\circ} \mathrm{C}$, and with type $1\left(K=0.01 \mathrm{~mm}^{2} / \mathrm{s}^{2}\right)$ at the temperatures of $60^{\circ} \mathrm{C}, 80^{\circ} \mathrm{C}$ (Tab. 7 ).

The two Ubbelohde viscometers with type $3 \mathrm{C}$ $\left(K=3 \mathrm{~mm}^{2} / \mathrm{s}^{2}\right)$ were used for the determination of kinematic viscosity values of APN415 at the temperatures of $20^{\circ} \mathrm{C}$ and $25^{\circ} \mathrm{C}$, with type $3\left(K=1 \mathrm{~mm}^{2} / \mathrm{s}^{2}\right)$ at the temperatures of $40^{\circ} \mathrm{C}$, with type $2 \mathrm{~B}\left(K=0.5 \mathrm{~mm}^{2} / \mathrm{s}^{2}\right)$ at the temperatures of $60^{\circ} \mathrm{C}$ and with type $2\left(K=0.1 \mathrm{~mm}^{2} / \mathrm{s}^{2}\right)$ at the temperatures of $80^{\circ} \mathrm{C}$ (Tab. 8).

The internal diameter of each capillary has been manufactured in accordance with the German standard DIN 51562-1:1999; 283-mm length and $18 \mathrm{~mL}$ measuring volume. UME Viscosity Laboratory maintains its own primary viscosity scale, based upon the internationally agreed value of distilled water at $20^{\circ} \mathrm{C}$ of $1.0034 \mathrm{~mm}^{2} / \mathrm{s}$.

Method 2, the Stabinger viscometer was used to determine the viscosity values of reference liquids. The apparatus was calibrated by the manufacturer, using several density and viscosity standard reference fluids. The uncertainty of the temperature measurement is $0.02 \mathrm{~K}$
Table 7. APN7.5 Reference liquid (Method 1).

\begin{tabular}{lll}
\hline Temperature $\left({ }^{\circ} \mathrm{C}\right)$ & $\begin{array}{c}\text { Kinematic } \\
\text { viscosity }\left(\mathrm{mm}^{2} / \mathrm{s}\right)\end{array}$ & $\mathrm{U}^{\prime}(\boldsymbol{v})(\%)$ \\
\hline 20 & 12.4011 & 0.28 \\
25 & 10.5055 & 0.28 \\
40 & 6.7832 & 0.25 \\
60 & 4.2448 & 0.23 \\
80 & 2.9151 & 0.22 \\
\hline
\end{tabular}

Table 8. APN415 Reference liquid (Method 1).

\begin{tabular}{lcc}
\hline Temperature $\left({ }^{\circ} \mathrm{C}\right)$ & $\begin{array}{c}\text { Kinematic } \\
\text { viscosity }\left(\mathrm{mm}^{2} / \mathrm{s}\right)\end{array}$ & $\mathrm{U}^{\prime}(\boldsymbol{v})(\%)$ \\
\hline 20 & 1361.7885 & 0.38 \\
25 & 977.2290 & 0.38 \\
40 & 405.9990 & 0.34 \\
60 & 157.8822 & 0.34 \\
80 & 73.2143 & 0.32 \\
\hline
\end{tabular}

$(k=2)$. The uncertainty value of temperature measuring device was taken as $0.02 \mathrm{~K}$ and the standard uncertainty was calculated as $0.01 \mathrm{~K}$. The uncertainty of the dynamic viscosity is $1 \%(k=1)$. The overall uncertainty of the measurements (taking into account the purity and handling of the samples) is estimated to be $2 \%$. This equipment has also a vibrating-tube that permits measurements of the densities with an uncertainty of $0.0005 \mathrm{~g} / \mathrm{cm}^{3}(k=1)$ [2].

\subsection{Flow time measurement}

Flow-time measurements were performed by visual observation of the meniscus passing two ring marks at the viscometer using a stopwatch with resolution of $0.001 \mathrm{~s}$ [3].

\subsection{Temperature measurement}

The room temperature of viscosity laboratory of TUBITAK UME is $20^{\circ} \mathrm{C} \pm 1^{\circ} \mathrm{C}$.

A thermostatically controlled bath of $70 \mathrm{~L}$ is used in the measurements of viscometers with external cooling bath to provide the thermal equilibrium of measurements. Its performance was tested in the range from $10^{\circ} \mathrm{C}$ to $100^{\circ} \mathrm{C}$. Temperature stability is $\leq 0.01^{\circ} \mathrm{C}$.

Temperature measurements are realized by using two SPRT standard platinum resistance thermometers with the sensitivity of $0.1 \Omega /{ }^{\circ} \mathrm{C}$.

\section{Experimental setup}

First, the Ubbelohde viscometers were positioned in the bath vertically and waited for thermal equilibrium. For each reference liquids, the kinematic viscosity values were determined by the measurement method mentioned in the standard of DIN 51 562-1 and DIN 51 562-4. The primary viscosity measurements were 


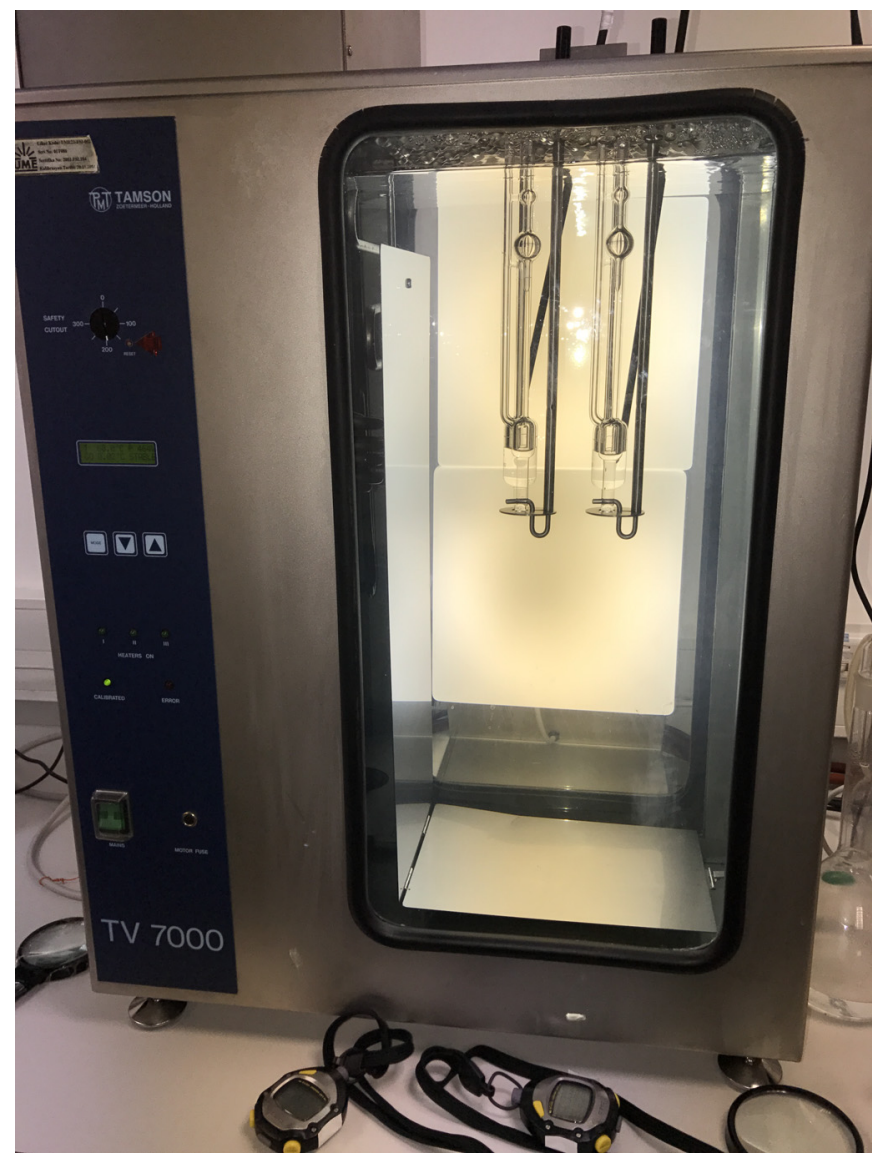

Fig. 1. Primary viscosity measurements system (Method 1).

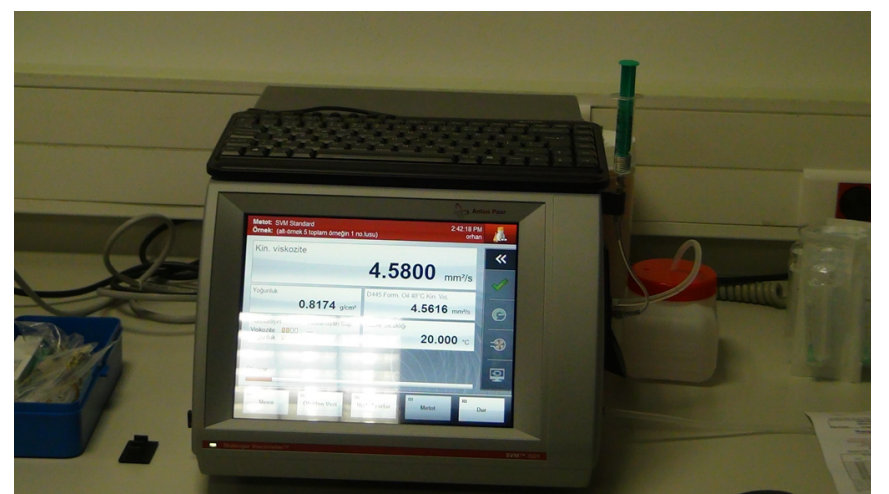

Fig. 2. Stabinger viscometer (Method 2).

realized by Ubbelohde viscometers seen in Figure 1. Before all these measurements, the primary viscometers had been characterized and their viscometer constants were determined. The calibration of the pairs of viscometers was usually performed by simultaneous direct comparison of two pairs of viscometers in the same temperature controlled bath. The different liquids with known viscosities were used for the realization of procedure.
The kinematic viscosity values of reference liquids (APS3, APN26, APN7.5 and APN 415) were measured with a $\mathrm{SVM}^{\mathrm{TM}} 3001$ Stabinger viscometer (Anton-Paar) at $20^{\circ} \mathrm{C}, 25^{\circ} \mathrm{C}, 40^{\circ} \mathrm{C}, 60^{\circ} \mathrm{C}$ and $80^{\circ} \mathrm{C}$. This instrument offers a $0.2-10000 \mathrm{mPas}$ with a reproducibility $0.35 \%$ of the measured value (Fig. 2).

\section{Measurements and results}

The viscosities were measured using either Ubbelohde viscometers or an automated SVM 3001 Anton Paar Stabinger viscometer.

The measurements were realized with 8 groups of Ubbelohde type two glass capillary viscometers. The uncertainty value of each kinematic viscosity was calculated according to DIN 510562-4 standard.

For the relative variance of the viscosity, a value determined with two viscometers and using two thermometers was $[4,5,6]$

$$
\begin{gathered}
\left(S_{v}^{\prime}\right)^{2}=\left(S_{K}^{\prime}\right)^{2}+\frac{1}{2} \cdot\left[\left(S_{\mathrm{Uhr}}^{\prime}\right)^{2}+\left(S_{\vartheta, V}^{\prime}\right)^{2}+\left(S_{N}^{\prime}\right)^{2}\right. \\
\left.+\left(S_{t}^{\prime}\right)^{2}\right], \\
\quad U_{v}^{\prime}=2 \cdot S_{v}^{\prime} \quad k=2 .
\end{gathered}
$$

The contributions of these quantities must have been taken into account for the determination of the measurement uncertainty. The respective relative empirical standard deviations and the relative variance supplied with the corresponding index were indicated as $S^{\prime}$ and $S^{\prime 2}$ respectively $[4,5]$.

-Viscometer constant, $S_{K}^{\prime 2}$

If the relative uncertainty of the constant $U_{K}^{\prime}$ was stated according to the calibration certificate for $k=2$, the variance was given by $[4,5]$.

$$
\left(S_{K}^{\prime}\right)^{2}=\frac{1}{4}\left(U_{K}^{\prime}\right)^{2}
$$

-Timing device, $S^{\prime}{ }_{\mathrm{Uhr}}^{2}$

It was assumed that two timing devices were used corresponding to the usual practice to perform measurements with both viscometers parallel in time in the same thermostat bath [4,5].

$$
\left(S_{\mathrm{Uhr}}^{\prime}\right)^{2}=\frac{1}{3}\left(U_{\mathrm{Uhr}}\right)^{2}
$$

-Temperature measurement, $S_{\theta, v}{ }^{2}$

The contribution of the temperature measurement $\left(S_{\theta}\right)$ to the uncertainty of the viscosity determination included the calibration uncertainty of the temperature measuring device at the particular measuring temperature as well as the temperature gradients in the thermostat bath, and was given by,

$$
\left(S_{\vartheta, v}^{\prime}\right)^{2}=\frac{1}{3}\left(S_{\vartheta} \cdot U_{v}\right)^{2}
$$




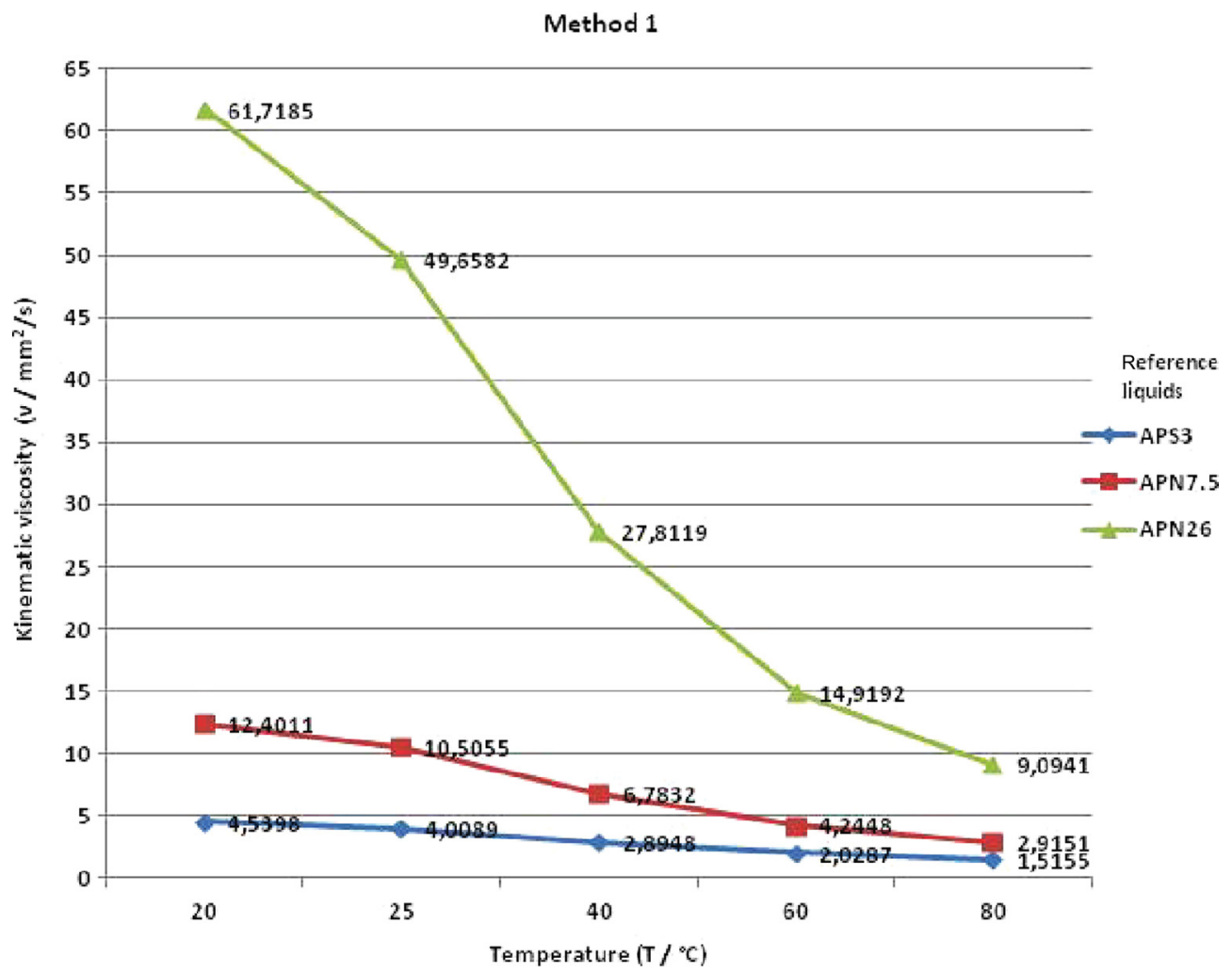

Fig. 3. Graphics of Kinematic viscosity value and temperature for reference liquids APS3, APN7.5 and APN26 in Method 1.

Method 2

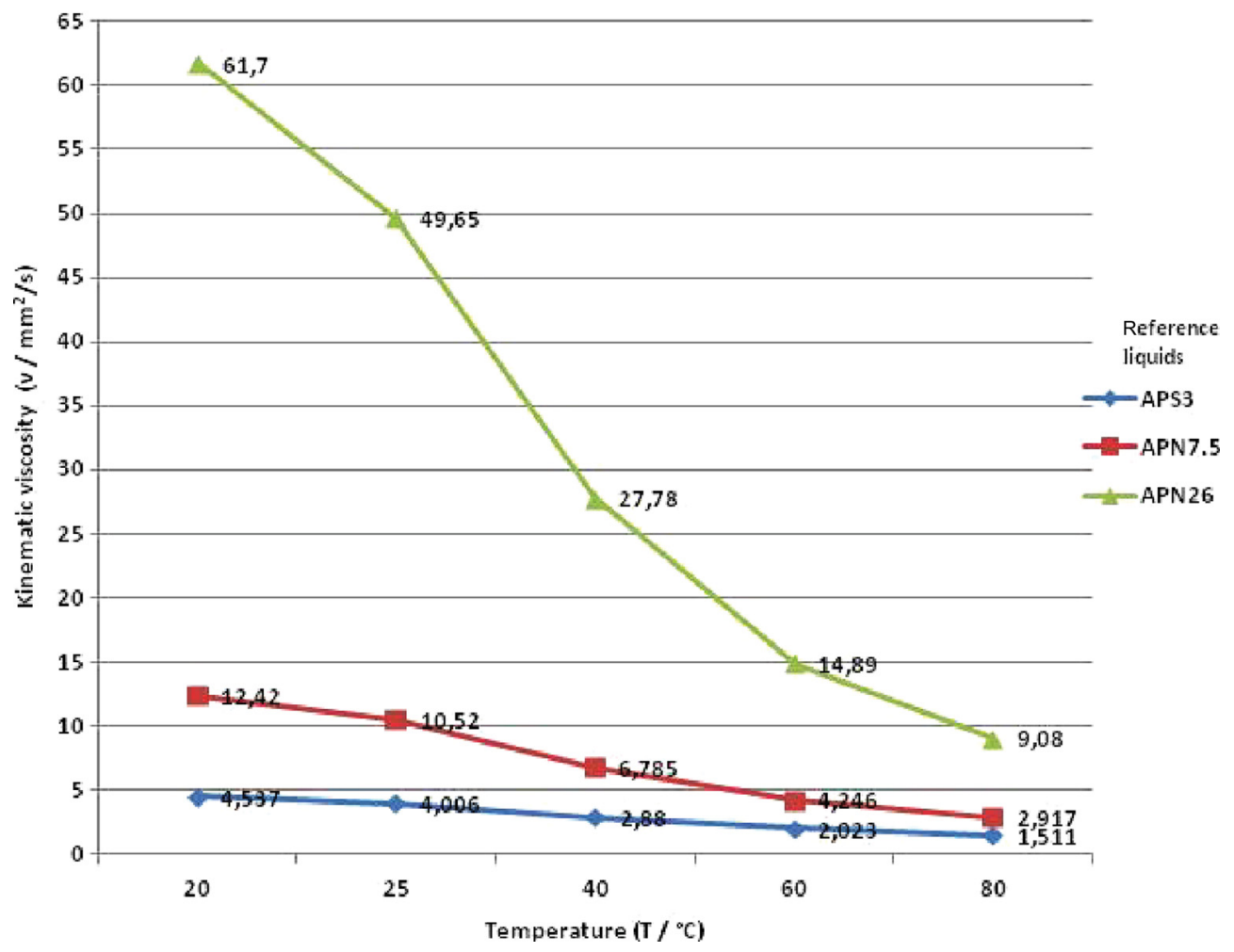

Fig. 4. Graphics of Kinematic viscosity value and temperature for reference liquids APS3, APN7.5 and APN26 in Method 2. 


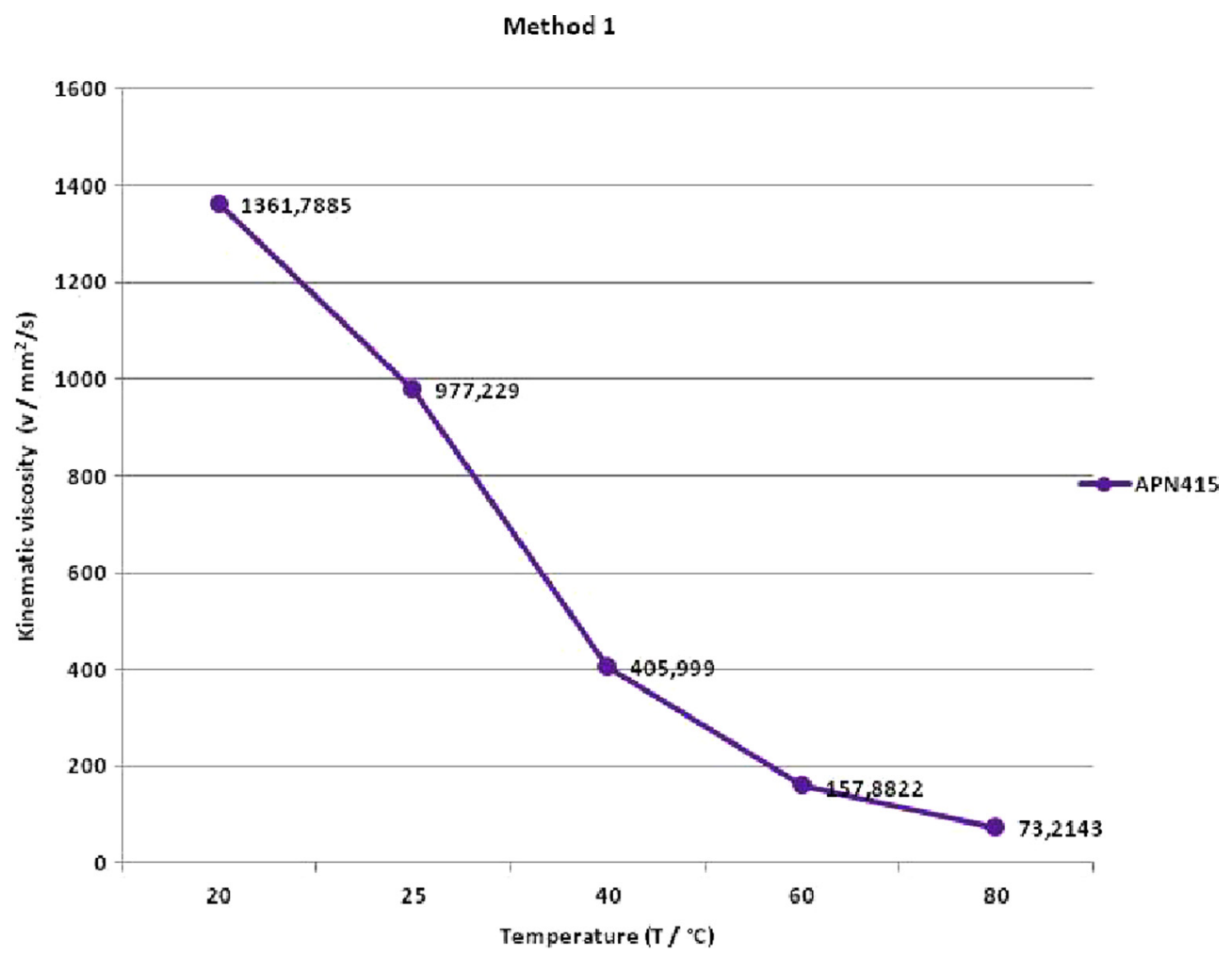

Fig. 5. Graphics of Kinematic viscosity value and temperature for reference liquids APN415 in Method 1.

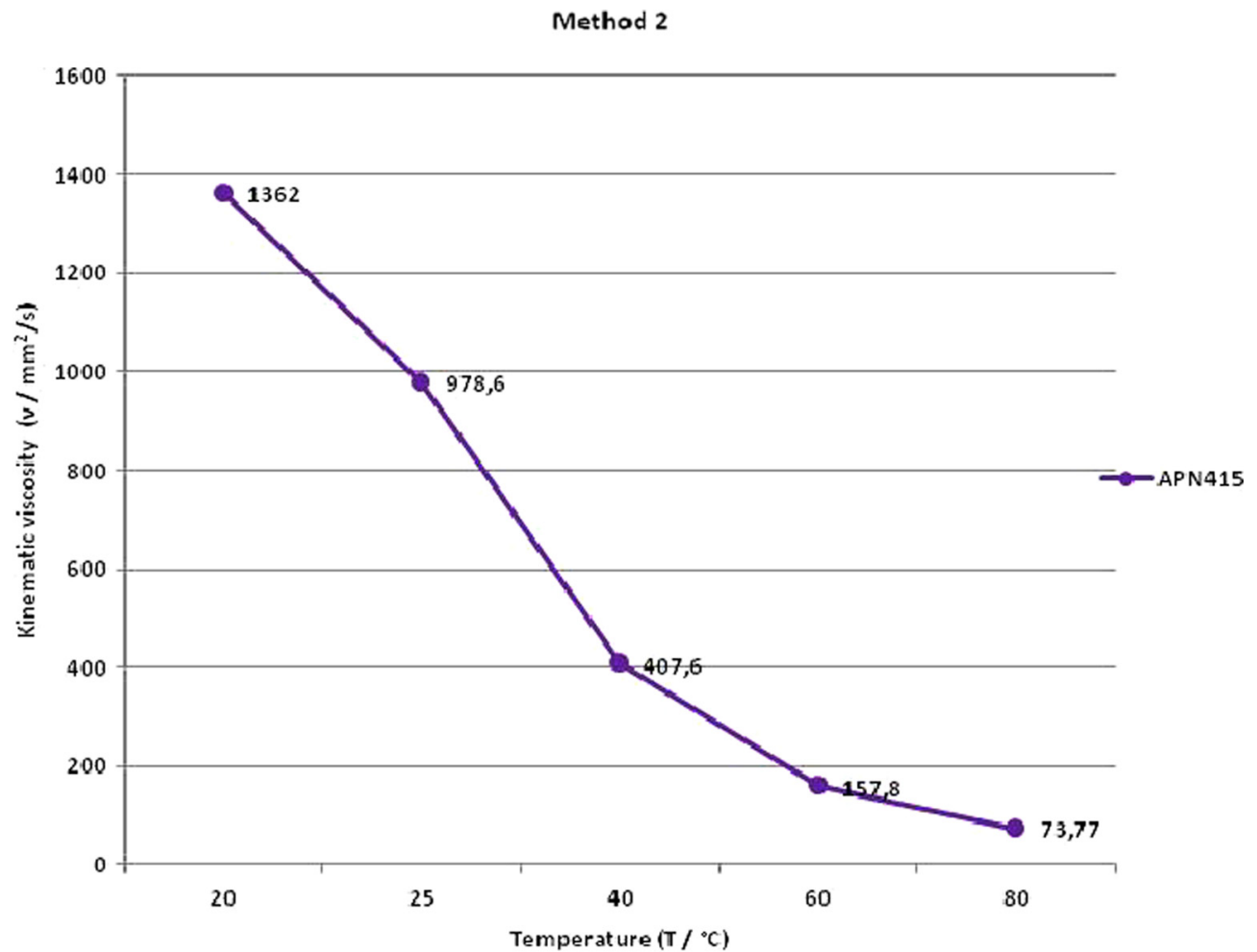

Fig. 6. Graphics of Kinematic viscosity value and temperature for reference liquid APN415 in Method 2. 
Table 9. Relative variance of flow time depending on $n$ and $\varepsilon_{t}$.

\begin{tabular}{cccr}
\hline$n$ & $\varepsilon_{t}$ & $F$ & $S_{t}^{\prime 2}=\frac{\left(\varepsilon_{t} \cdot F\right)^{2}}{n}$ \\
\hline 3 & $1 \cdot 10^{-3}$ & 0.591 & $11.6 \cdot 10^{-8}$ \\
3 & $2 \cdot 10^{-3}$ & 0.591 & $46.7 \cdot 10^{-8}$ \\
4 & $1 \cdot 10^{-3}$ & 0.486 & $5.9 \cdot 10^{-8}$ \\
4 & $2 \cdot 10^{-3}$ & 0.486 & $23.6 \cdot 10^{-8}$ \\
5 & $1 \cdot 10^{-3}$ & 0.430 & $3.7 \cdot 10^{-8}$ \\
5 & $2 \cdot 10^{-3}$ & 0.430 & $14.9 \cdot 10^{-8}$ \\
\hline
\end{tabular}

-Inclination error, $S_{N}^{\prime 2}$

The viscometer was inserted into a holder equipped with a flat top plate which served for the defined fixation of the viscometer in the thermostatic bath. The deviation of the capillary axis from the vertical to the top plate of the holder must not have exceeded $2[4,5]$.

$$
\begin{gathered}
\left(S_{N}^{\prime}\right)^{2}=\frac{1}{3}\left(\frac{C-C^{\prime}}{C}\right)^{2}=\frac{1}{3}\left(1-\frac{\cos \theta}{\cos \theta_{0}}\right)^{2} \\
C^{\prime}=C \cdot \frac{\cos \theta}{\cos \theta_{0}} \theta=2^{\circ}, \theta_{0}=0 .
\end{gathered}
$$

-Flow time, $S_{t}^{\prime 2}$

This contribution comprised deviations due to visual or automatic recording of the meniscus passages as well as changes in temperature as to time.

For each reference liquids, the mean value $(t)$ of the flow time $\left(t_{i}\right)$ was calculated as below. As well as the relative difference between the longest and shortest flow time was determined $[4,5]$.

$$
t=\frac{1}{n} \sum t_{i} \quad \varepsilon_{t}=\frac{t_{\max }-t_{\min }}{t}
$$

$n$ as the number of flow times of measurement series, $\varepsilon_{t}$ as the relative range of flow in measurement series of a viscometer and $F$ as multiplication factor were given in Table $9[4,5]$.

Measurements of viscosity were also performed in the temperature range of $20^{\circ} \mathrm{C}-80^{\circ} \mathrm{C}$ at atmospheric pressure using an automated SVM 3001 Anton Paar Stabinger viscometer.

These viscosity measurements are based on a tube filled with the sample in which floats a hollow measuring rotor. Due to its low density, the rotor is centered in the heavier liquid by buoyancy forces. The rotor is forced to rotate by shear stresses in the liquid and is guided axially by a built-in permanent magnet, which interacts with a soft iron ring. The rotating magnetic field delivers the speed signal and induces eddy currents in the surrounding copper casing. These eddy currents are proportional to the speed of the rotor and exert a retarding torque on the rotor. Two different torques influence the speed of the measuring rotor. At equilibrium, the two torques are equal and the viscosity can be traced back to a single speed measurement. The SVM 3001 uses Peltier elements for fast and efficient thermal stability. The temperature uncertainty is $\pm 0.02 \mathrm{~K}(k=2)$ from 288.15 to $378.15 \mathrm{~K}$. The precision of the dynamic viscosity measurements is $\pm 0.5 \%$. The overall uncertainty of the measurements (taking into account the purity and handling of the samples) is estimated to be $2 \%[2,7-9]$.

\section{Conclusion}

In this paper, the viscosity measurements were realized both glass capillary viscometers and Stabinger viscometer by using certified reference liquids. In first method, the Ubbelohde viscometers were used to find the flow time of liquids and then the kinematic viscosity was calculated. In second method, the Stabinger viscometers measured the dynamic viscosity and the kinematic viscosity was found using density and dynamic viscosity [6].

The measurement results of kinematic viscosity values for both methods were so close as it could be seen in Figures 3-6.

The evaluation of expanded uncertainty of Method 1 is mainly affected by the individual contributions of the viscometer constant and flow time.

The main idea of this study that using Stabinger viscometer to measure the viscosity value of liquids is easy and accurate way due to the high uncertainty value. Providing the traceability by Ubbelohde viscometers, the results can be used to give certificate for the reference liquids and calibration of viscometers. This paper showed the procedure of the determination of viscosity value of each liquids by using Ubbelohde viscometers and Stabinger viscometer at different temperatures. The values are very similar that the evaluation can be realized in uncertainty budget of the Stabinger viscometer. According to this, the evaluation can be given to decrease the uncertainty values of Method 2 in future study.

\section{References}

1. J.G. Webster, Mechanical Variables Measurement Solid, Fluid and Thermal, CRC Press LLC, USA, 2000

2. X. Parades, O. Fandino, A.S. Pensado, M.J.P. Comunas, J. Fernandez, Experimental density and viscosity measurements of di(2ethylhexyl)sebacate at high pressure, J. Chem. Thermodyn. 44, 38-43 (2012)

3. S. Lorefice, F. Saba, The Italian primary kinematic viscosity standard: the viscosity scale, Measurement 112, 1-8 (2017)

4. DIN 51562-1, Determination of the Kinematic Viscosity Using the Standard Design Ubbelohde Viscometer (German Institute for Standardization DIN, Berlin, Germany, 1999)

5. DIN 51562-4, Measurement of Kinematic Viscosity by means of the Ubbelohde Viscometer (German Institute for Standardization DIN, Berlin, Germany, 1999) 
6. H. Bauer, G. Klingenberg, EUROMET.M.V-K3 Key Intercomparison of Liquid Viscosity Measurements (PTB-ThEx22, Bericht, 2001), p. 75

7. D.H. Lee, J.M. Jung, S.Y. Kim, K.T. Kim, Y.I. Cho, Comparison tests for plasma viscosity measurements, Int. Commun. Heat Mass Transf. 39, 1474-1477 (2012)
8. S. Geacai, O. Iulian, I. Nita, Measurement, correlation and prediction of biodiesel blends viscosity, Fuel 143, 268-274 (2015)

9. J.L. Camas-Anzuetoa, J. Gómez-Péreza, R. Meza-Gordilloa, G. Anzueto-Sánchezb, M. Pérez-Patricioa, F.R. LópezEstradaa, M. Abud-Archilaa, C. Ríos-Rojasa, Measurement of the viscosity of biodiesel by using an optical viscometer, Flow Meas. Instrum. 54, 82-87 (2017)

Cite this article as: G.S. Sariyerli, O. Sakarya, U.Y. Akcadag, Comparison tests for the determination of the viscosity values of reference liquids by capillary viscometers and stabinger viscometer SVM 3001, Int. J. Metrol. Qual. Eng. 9, 7 (2018) 